Journal of the Rubber Research Institute of Sri Lanka, (2009) 89, 46-57

\title{
Growth of young budding plants as affected by type and packing density of the potting media
}

\author{
R S Dharmakeerthi*, E A D Siriwardana**, V U Edirimanna* \\ and $\mathbf{J}$ A S Chandrasiri*
}

Received 26 December 2008; Accepted 20 November 2009

\begin{abstract}
The effects of potting media and the degree of compaction on shoot and root growth of Hevea brasiliensis (A. Juss.) Muell. Arg. plants raised using young budding technique were determined in this study. Soils were mixed with coir dust or saw dust to a ratio of either 1:1 or 3:1 and filled into polybags with two compaction levels. Shoot diameter and dry weight, and root dry weights were measured at 12 weeks after planting and 6 weeks after cut-back. Percentages of buddable plants, grafting success, scion death and sprouting were also measured. Plants in soil-coir dust 3:1 ratio (SC31) recorded the highest seedling growth (7.2 $\mathrm{mm}$ in diameter) as well as scion growth $(6.2 \mathrm{~mm}$ in diameter) while the lowest growth was observed in soil only (seedling diameter of $6.5 \mathrm{~mm}$ ) and in soil-saw dust 3:1 (SS31) media (scion diameter of $4.4 \mathrm{~mm}$ ). Total root weight also was significantly higher in SC31 compared to those in other potting media, both at 12 weeks after planting $\left(3.36 \mathrm{~g}_{\text {plant }}{ }^{-1}\right)$ and 6 weeks after cut-back (7.99 $\left.\mathrm{g}_{\text {plant }}{ }^{-1}\right)$. Feeder root density was significantly low in currently adopted soil only treatments at both growth stages. The plants in the soil and coir dust mixed polybags had higher probability of attaining buddable girth than plants in other treatments. The level of compaction in the potting media had no significant impact on shoot or root growth parameters measured. This study showed that growth of young budding plants could significantly be improved by using a potting media of soil and coir dust with a ratio of 3:1. Relative advantages of having a polybag plant with a dense root system are discussed in relation to stress mitigation both in the nursery and field.
\end{abstract}

Key words: coir dust, Hevea brasiliensis, root growth, saw dust, soil compaction, young budding

\section{Introduction}

Plant growth is affected by properties of the growing media. physical, chemical, and biological Currently recommended potting media

* Rubber Research Institute of Sri Lanka, Dartonfield, Agalawatta, Sri Lanka

* Dept. of Soil Science, Faculty of Agriculture, University of Peradeniya, Peradeniya 
R S Dharmakeerthi et al.

for young budding nurseries by the Rubber Research Institute of Sri Lanka (RRISL) is the fertile top soil that has been sieved to remove gravel and stone particles. However, the availability of fertile top soil in many rubber plantations and commercial rubber nurseries is inadequate due to repeated establishment of nurseries in the same place over a long period. The available sub soils are high in clay content, low in organic $\mathrm{C}$ content and possess poor chemical and physical properties for crop growth. Although soil chemical fertility of available sub-soil could be improved by applying fertilizers, physical fertility still remains as a barrier for growth of young budding plants.

Information on the effect of soil physical properties on the growth of rubber plants raised by young budding technique is not available. However, under field conditions, Soong (1976) has observed more feeder roots in rubber plants grown on a very sandy soil than on a clayey soil in Malaysia. Samarappuli et al. (1996) also observed that root density of field grown rubber plants in Sri Lanka was negatively related to soil bulk density and positively related to organic $\mathrm{C}$ content. During the filling of polybags with available soil, nursery workers apply different levels of compaction. Compaction affects the pore size distribution and consequently the water and air retention of the soil (Kay, 1998) and it increases the root penetration resistance as well. The increased proportion of smaller pores during compaction results in soil behaving as if it were a finer textured soil (Greacen and Sands, 1980).

Shoot growth of Hevea plants raised in polybags has been improved by applying chemical fertilizers (Yogaratnum et al., 1984; Dharmakeerthi et al., 1997), compost or mixing the sub soil with organic residues such as coir dust (Hettiarachchi, 2002). However, the effect of such materials on the root growth of Hevea nursery plants has only sparsely studied. Moreover, Dharmakeerthi et al. (2008) observed that density of feeder roots in sub-soil filled polybags is decreased by about $60 \%$ around $4-6$ weeks after the cut-back of successfully grafted stock seedlings. Resulting low root activity and its coincidence with a very critical growth stage in young budding plants (Dharmakeerthi et al., 2008) demands management practices that would retain more feeder roots at the critical growth stage, in addition to improved plant growth medium for young budding nurseries.

It is hypothesized that, by creating a more favorable physical environment in the potting media, there is the possibility of retaining a higher root density at the critical growth stage of young budding plants. Hence, this study determines the effect of mixing of soil with organic materials and of compaction during bag filling on the root and shoot growth of young budding plants. 
Potting media and compaction on growth of young buddings

\section{Materials and Methods}

The study was undertaken at the Dartonfield Estate of RRISL from October 2007 to June 2008. There were 10 treatment combinations of two factors, namely five different potting media and two compaction levels. Soil only and soil plus coir dust or saw dust mixed to $1: 1$ and $3: 1$ ratios (volume basis) were used as potting media. Each potting medium was packed into polybags $(15 \mathrm{~cm} \times 37 \mathrm{~cm}$ lay flat dimensions) to obtain two compaction levels. Preliminary tests were carried out to determine the weight of each potting mixture required to simulate loose compaction and maximum possible compaction that an average nursery worker could exert during bag filling. Bags were filled using these weights for a given potting media and compaction level. Since the compatibility of the potting mixtures is different, resultant bulk densities of the polybags were also different (Table 1).

Top soil from Agalawatta series were used for the experiment. Soil, coir dust and saw dust used for the experiment were characterized for $\mathrm{pH}$, organic $\mathrm{C}$ content, total $\mathrm{N}$, total $\mathrm{P}$, exchangeable $\mathrm{K}, \mathrm{Mg}$ and $\mathrm{Ca}$ as well as total micro nutrients such as $\mathrm{Zn}, \mathrm{Fe}$ and $\mathrm{Cu}$ (Table 2). The $\mathrm{C}: \mathrm{N}$ ratio of coir dust and saw dust were 131:1 and 295:1, respectively.

Table 1. Bulk densities of different potting media at bag filling and at the end of the experiment

\begin{tabular}{llllll}
\hline \multirow{2}{*}{ No. } & \multirow{2}{*}{ Potting media } & Compaction & Code & \multicolumn{2}{c}{ Bulk density $\left(\mathbf{M g ~ m}^{-3}\right)$} \\
\cline { 5 - 6 } & & & initial & end \\
\hline 1 & Soil only & Loose & S-L & 1.05 & 1.26 \\
2 & Soil only & Compacted & S-C & 1.20 & 1.34 \\
3 & Soil : coir dust (1:1 ratio) & Loose & SC11-L & 0.68 & 0.80 \\
4 & Soil : coir dust (1:1 ratio) & Compacted & SC11-C & 0.84 & 0.95 \\
5 & Soil : coir dust (3:1 ratio) & Loose & SC31-L & 0.96 & 1.09 \\
6 & Soil : coir dust (3:1 ratio) & Compacted & SC31-C & 1.06 & 1.06 \\
7 & Soil : saw dust (1:1 ratio) & Loose & SS11-L & 0.74 & 0.77 \\
8 & Soil : saw dust (1:1 ratio) & Compacted & SS11-C & 0.79 & 0.82 \\
9 & Soil : saw dust (3:1 ratio) & Loose & SS31-L & 0.88 & 1.01 \\
10 & Soil : saw dust (3:1 ratio) & Compacted & SS31-C & 0.96 & 1.00 \\
\hline
\end{tabular}


R S Dharmakeerthi et al.

Table 2. Properties of soil, coir dust and saw dust used in the experiment

\begin{tabular}{lrrr}
\hline Property & Soil & Coir dust & Saw dust \\
\hline $\mathrm{pH}$ & 4.75 & 6.32 & 6.04 \\
Organic C (\%) & 1.7 & 31.3 & 50.9 \\
Total N (\%) & 0.101 & 0.239 & 0.173 \\
Total P (\%) & 0.51 & 0.56 & 0.52 \\
Exchangeable K (ppm) & 39 & 2020 & 1377 \\
Exchangeable Mg (ppm) & 15 & 103 & 36 \\
Exchangeable Ca (ppm) & 88 & 503 & 1123 \\
Total Zn (ppm) & 84 & 15 & 259 \\
Total Fe (ppm) & 118 & 45 & 1631 \\
Total Cu (ppm) & 6.9 & 2.4 & 0.2 \\
\hline
\end{tabular}

The 10 treatment combinations were replicated 20 times and arranged according to a randomized complete block design. Sowing of germinated seeds in polybags was done in November 2007 and grafted with clone RRIC 121 in March 2008. All management practices in the young budding nursery were conducted as recommended by the Rubber Research Institute of Sri Lanka (Tillekeratne and Nugawela, 2001) except that two applications of 1 or $2 \mathrm{~g}$ of $\mathrm{N}$ per bag (depending on the $\mathrm{C}$ contents in the bag) were applied to coir dust and saw dust mixed poly bags to prevent any $\mathrm{N}$ deficiency in these bags due to immobilization. $\mathrm{N}$ requirement was calculated based on the amount of $\mathrm{N}$ required to keep the $\mathrm{C}: \mathrm{N}$ ratio of the potting media same as that of the soil only treatment (16.8) and rounding it to the nearest digit.

Diameter of the seedling (at 12 weeks after planting) and scion (at 6 weeks after cut-back) were measured $\left(D_{\text {shoot }}\right)$. At these ages 6 or 5 plants were destructively sampled to estimate the dry matter contents in shoot $\left(\mathrm{W}_{\text {shoot }}\right)$, tap root $\left(\mathrm{W}_{\text {tap }}\right)$, lateral roots $\left(\mathrm{W}_{\text {lat }}\right)$ and feeder roots $\left(\mathrm{W}_{\text {feed }}\right)$ by oven drying them at $60^{\circ} \mathrm{C}$ for a constant weight. During destructive sampling, utmost care was taken to collect almost the entire root system intact. However, we observed that few roots have grown out through the drainage holes in the polybag after about 4 months. Since the excavation of these roots could disturb the growth of other plants, they were not sampled. Soil and dust particles adhered on to the root system were removed by washing them gently under running water over a $0.5 \mathrm{~mm}$ sieve. Roots initiating from the tap roots were considered as lateral roots and fibrous roots arising from laterals were considered as feeder roots. All decaying (brown) roots were considered as dead or near dead roots and were removed before measurements. Based on these data the shoot-root ratio (S/R) was calculated. Percentage of buddable plants i.e. seedling diameter greater than $6 \mathrm{~mm}$ at 12 weeks (BD), 
Potting media and compaction on growth of young buddings

grafting success (GS), sprouting (SP) and scion death $(\mathrm{SD})$ were also recorded.

Quantitative data were statistically analysed using the Proc GLM procedure while percentage data were analysed using Proc CATMOD in SAS software package (SAS Institute, 1996). Since the degree of compaction among potting media were different, effect of compaction was considered nested within the effect of potting media. Further the percentages of successes and failures in grafting, success, sprouting and die-back due to the effect of potting medium and compaction were analyzed using Chi-square tests. Both medium and compaction were considered as fixed effects in the ANOVA and these variables were considered statistically significant, if $p<0.1$.

\section{Results and discussion}

The bulk density of the potting media increased with time except for
SC31-C where the bulk density did not changed. In cases where the bulk density increased, the increase was more in the loosely packed polybags compared to that in densely packed polybags (Table 1). It was observed that the compaction of the potting media was rapid during the first two months (data not presented). Watering during the experimental period could have largely responsible for the settling in of the potting media. Plants in the polybags were watered to saturation at 4-day intervals during the non rainy days.

Analysis of variance indicated that potting media had a very high influence on the growth of both shoot and root but the level of compaction has influenced only on lateral and feeder root growth after cut-back (Table 3).

Table 3. Analysis of variance of different parameters measured in the study

\begin{tabular}{|c|c|c|c|c|c|c|c|}
\hline Source of error & D $_{\text {shoot }}$ & $\mathbf{W}_{\text {shoot }}$ & $\mathbf{W}_{\text {tap }}$ & $\mathbf{W}_{\text {lat }}$ & $\mathbf{W}_{\text {feed }}$ & $\mathbf{W}_{\text {tot }}$ & $\mathbf{S} / \mathbf{R}$ \\
\hline \multicolumn{8}{|l|}{12 weeks after planting } \\
\hline Medium & $* *$ & $\dagger$ & $\dagger$ & Ns & $* *$ & $*$ & $\mathrm{~ns}$ \\
\hline Compaction (Medium) & ns & Ns & ns & Ns & ns & $\mathrm{ns}$ & ns \\
\hline \multicolumn{8}{|l|}{6 weeks after cut-back } \\
\hline Medium & $* * *$ & $* *$ & $* *$ & $* *$ & $*$ & $* *$ & ns \\
\hline Compaction (Medium) & ns & Ns & ns & $* *$ & $* *$ & ns & ns \\
\hline
\end{tabular}

$* * *, * *, *$ and $\dagger$ are significance levels $\mathrm{p}<0.001,0.01 .0 .05$ and 0.1 , respectively ns - not significantly different at $\mathrm{p}<0.1$ 
R S Dharmakeerthi et al.

\section{Effect of potting media \\ Shoot growth}

Seedling growth, as indicated by the diameter and dry matter accumulation, was significantly high in coir dust mixed poly bags compared to that in soil only bags (Table 4). Even though the seedling growth in saw dust mixed bags were not statistically different from that in either coir dust mixed or soil only treatments, the growth is lower than that in coir dust mixed bags. The growth of the scion after cut-back however, was significantly lower in both saw dust and soil only treatments compared to coir dust mixed treatments. There was no significant difference among plants in soil only and saw dust media. Plants in SC31 gave the highest seedling growth (7.2 $\mathrm{mm}$ in diameter) as well as scion growth $(6.2 \mathrm{~mm}$ in diameter) while the lowest growth were observed in soil only media (seedling diameter of 6.5 $\mathrm{mm}$ ) or in SS31 media (scion diameter of $4.4 \mathrm{~mm}$ ). Soils used for this study is top soil with relatively high fertility level (Table 4) and therefore a significant growth improvement in soil mixed with saw dust treatments was not evident. The growth response of young budding plants could expected to be different between unfertile sub soil and sub soil mixed with saw dust as observed by Hettiarachchi (2002) in poly bags planted with bare root budded stumps.

\section{Root growth}

Total root weight was significantly higher in SC31 treatment compared to those in other potting media both 12 weeks after planting (3.36 $\mathrm{g} \mathrm{plant}^{-1}$ ) and 6 weeks after cutback (7.99 $\mathrm{g} \mathrm{plant}^{-1}$ ) (Table 4). Feeder root density was significantly low in currently adopted soil only treatments at both growth stages while there was no significant difference among other three treatments. A better tap root growth also could be observed in SC31 treatment. Plants having a vigorously growing tap root would give a better anchorage to the plant against felling due to wind (Jeevaratnam, 1962) while plants with better feeder root system would absorb more water and nutrients particularly during the initial stages after field planting and combat early stresses better than other plants (Varghese et al., 2005). When considering both these aspects plants in SC31 media could expected to perform better than plants in the currently adopted soil only potting media. 
Potting media and compaction on growth of young buddings

Table 4. Shoot and root growth and shoot-root ratio as affected by the potting media at two different growth stages of young budding plants

\begin{tabular}{|c|c|c|c|c|c|c|c|}
\hline \multirow[t]{2}{*}{ Medium } & $\mathbf{D}_{\text {shoot }}$ & $\mathbf{W}_{\text {shoot }}$ & $\mathbf{W}_{\text {tap }}$ & $\mathbf{W}_{\text {lat }}$ & $\mathbf{W}_{\text {feed }}$ & $\mathbf{W}_{\text {tot }}$ & \multirow[t]{2}{*}{$\mathbf{S} / \mathbf{R}$} \\
\hline & $\mathrm{mm}$ & \multicolumn{5}{|c|}{ 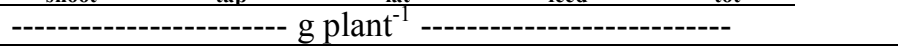 } & \\
\hline \multicolumn{8}{|c|}{12 weeks after planting } \\
\hline Soil & $6.5^{\mathrm{B}}$ & $7.34^{\mathrm{B}}$ & $1.79^{\mathrm{AB}}$ & $0.19^{\mathrm{A}}$ & $0.51^{\mathrm{BC}}$ & $2.49^{\mathrm{B}}$ & $3.10^{\mathrm{A}}$ \\
\hline $\mathrm{SC} 11$ & $7.1^{\mathrm{A}}$ & $9.55^{\mathrm{A}}$ & $1.64^{\mathrm{B}}$ & $0.18^{\mathrm{A}}$ & $0.83^{\mathrm{B}}$ & $2.65^{\mathrm{B}}$ & $3.82^{\mathrm{A}}$ \\
\hline SC31 & $7.2^{\mathrm{A}}$ & $9.76^{\mathrm{A}}$ & $2.11^{\mathrm{A}}$ & $0.17^{\mathrm{A}}$ & $1.08^{\mathrm{A}}$ & $3.36^{\mathrm{A}}$ & $3.03^{\mathrm{A}}$ \\
\hline SS11 & $6.6^{\mathrm{B}}$ & $8.46^{\mathrm{AB}}$ & $1.55^{\mathrm{B}}$ & $0.11^{\mathrm{A}}$ & $0.95^{\mathrm{AB}}$ & $2.60^{\mathrm{B}}$ & $3.33^{A}$ \\
\hline SS31 & $6.9^{\mathrm{AB}}$ & $8.84^{\mathrm{AB}}$ & $1.65^{\mathrm{B}}$ & $0.08^{\mathrm{A}}$ & $0.89^{\mathrm{AB}}$ & $2.62^{\mathrm{B}}$ & $3.46^{\mathrm{A}}$ \\
\hline \multicolumn{8}{|c|}{6 weeks after cut-back } \\
\hline Soil & $5.0^{\mathrm{BC}}$ & $2.38^{\mathrm{BC}}$ & $4.00^{\mathrm{B}}$ & $0.21^{\mathrm{B}}$ & $0.18^{\mathrm{B}}$ & $4.39^{C}$ & $0.64^{\mathrm{A}}$ \\
\hline SC11 & $5.7^{\mathrm{AB}}$ & $2.83^{\mathrm{B}}$ & $5.14^{\mathrm{B}}$ & $0.42^{\mathrm{A}}$ & $0.49^{\mathrm{A}}$ & $6.06^{\mathrm{B}}$ & $0.47^{\mathrm{A}}$ \\
\hline SC31 & $6.2^{\mathrm{A}}$ & $3.81^{\mathrm{A}}$ & $6.88^{\mathrm{A}}$ & $0.52^{\mathrm{A}}$ & $0.59^{\mathrm{A}}$ & $7.99^{\mathrm{A}}$ & $0.49^{\mathrm{A}}$ \\
\hline SS11 & $5.2^{\mathrm{BC}}$ & $2.29^{\mathrm{BC}}$ & $3.99^{\mathrm{B}}$ & $0.25^{\mathrm{B}}$ & $0.47^{\mathrm{A}}$ & $4.71^{\mathrm{BC}}$ & $0.48^{\mathrm{A}}$ \\
\hline SS31 & $4.4^{\mathrm{C}}$ & $1.79^{\mathrm{C}}$ & $4.27^{\mathrm{B}}$ & $0.21^{\mathrm{B}}$ & $0.73^{\mathrm{A}}$ & $5.21^{\mathrm{BC}}$ & $0.33^{\mathrm{A}}$ \\
\hline
\end{tabular}

Values followed by the same letter in a column and within an age category are not significantly different at $\mathrm{p}<0.05$

In an earlier experiment Dharmakeerthi and co workers have observed changes in the root system after cut back where feeder root length was reduced by about $60 \%$ around 4-6 weeks after cut back (Dharmakeerthi et al. 2008). In that experiment they have used poly bags filled with sub soil from Boralu series. Root measurements made in the current experiment also support this observation. Although the $\mathrm{W}_{\text {tap }}$ and $\mathrm{W}_{\text {lat }}$ has increased with time, $\mathrm{W}_{\text {feed }}$ has decreased in all treatments (Table 4). However, plants in polybags filled with a mixture of organic matter and soil has retained more feeder root density after cut-back compared to plants in the currently adopted soil only media. Dharmakeerthi et al. (2008) argued that 4-6 weeks after cut-back is a critical growth period for young budding plants where newly emerging scion could succumb easily to environmental stresses, particularly moisture and heat stresses during this period and that plant having more feeder root at this stage would be able withstand environmental stresses better than those plants having a weak feeder root system. If this hypothesis is acceptable, then plants in potting media with soil mixed with a organic residue (preferably with coir at $3: 1$ ratio according to this experiment) would be able to survive better in nurseries established in drier areas or during dry months.

Grafting, success, sprouting and scion die back

A significant degree of association among different potting media was observed on buddability and sprouting at 2 weeks after cut-back. Average diameter of seedling plants in all potting media was greater than the buddable diameter of $6.0 \mathrm{~mm}$. However, 


\section{R S Dharmakeerthi et al.}

the $\%$ of buddable plants was different among potting media where plants in the soil and coir dust mixed polybags had more probability in attaining buddable girth than plants in other treatments (Fig 1a). Better aeration and moisture relations in SC media could have resulted the better growth in these plants. Even though we applied additional $\mathrm{N}$ fertilizers to alleviate any $\mathrm{N}$ deficiency, availability of other essential micro nutrients could have been limited for
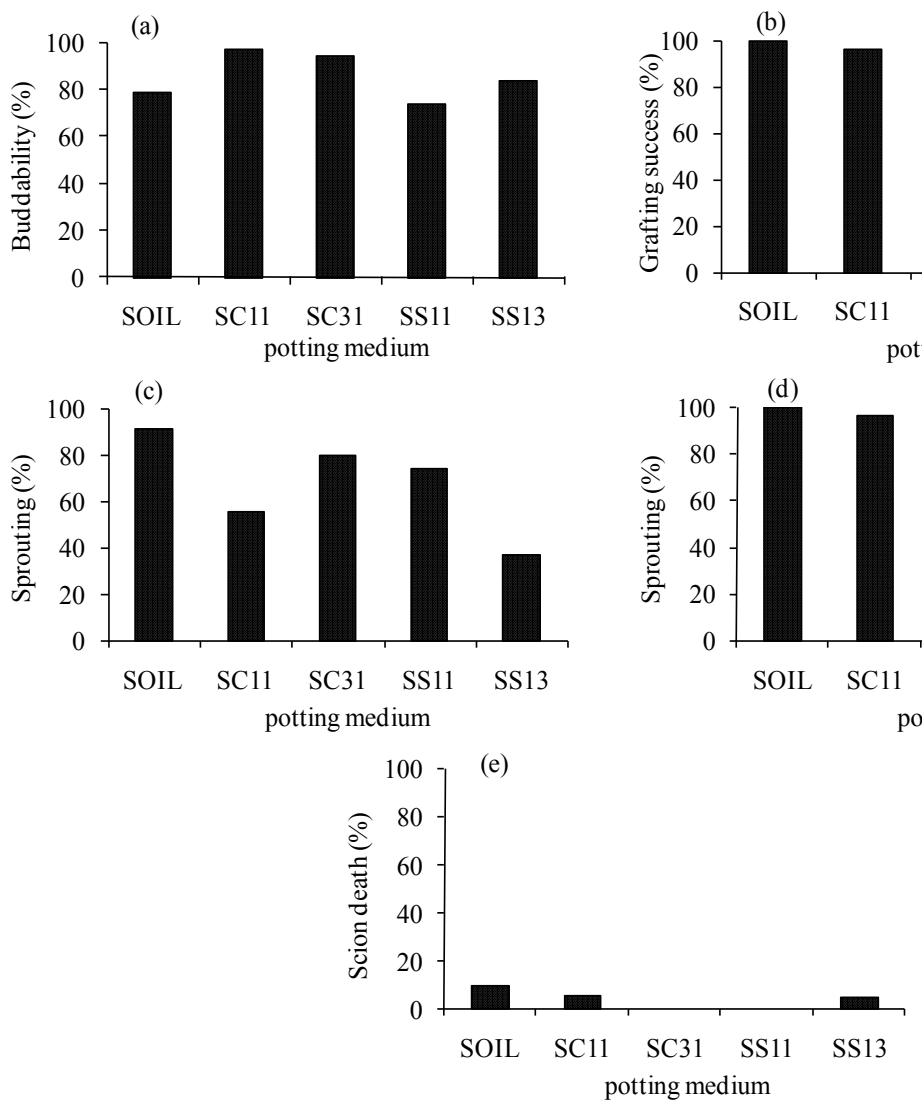

Fig 1. Percentages of buddable plants at 3 months after planting (a), grafting success (b), sprouting at 2 (c) or 4 (d) weeks after cut-back, and scion death (e) as affected by the potting media plants in saw dust mixed potting media. Grafting success has not been affected by the type of potting media (Fig 1b). Early sprouting appears to be affected when top soil is mixed with coir dust or saw dust Fig 1c). However, more than 90\% of the successfully grafted plants had been sprouted by 4 weeks after cut-back in all potting media but plants in SS31 (Fig 1d). The highest scion death was observed in the soil only treatment but they were not statistically different.
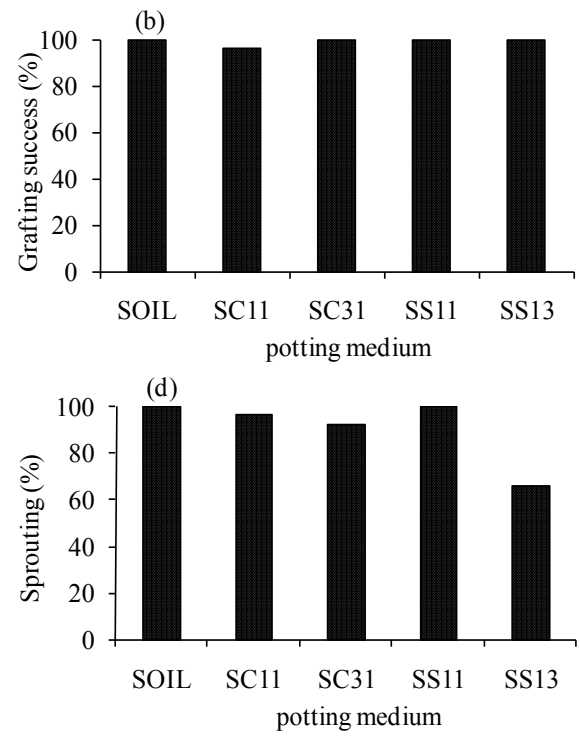
Potting media and compaction on growth of young buddings

Shoot-root interactions

At a given growth stage, plants have maintained a more or less similar shoot-root ratio irrespective of the potting media. The decrease in average $\mathrm{S} / \mathrm{R}$ from 3.3 at 12 weeks after planting to 0.5 at 6 weeks after cut-back could mainly be attributed to the removal of aerial parts of the seedling during the cut-back operation.

\section{Effect of compaction}

Shoot or root growth parameters of the seedling plants were not affected by the level of compaction in the potting media. Some researchers have proposed a maximum bulk density between 1.46 to $1.65 \mathrm{Mg} \mathrm{m}^{-3}$ beyond which root penetration is limited (Veihmeyer and Hendrickson, 1948). None of the treatments have exerted such a high compaction in our experiment (Table 1). Moreover, Blouin et al. (2004) observed that the compaction had an effect on pine seedling growth only when the water is a limiting factor. Buttery et al. (1998) also observed that effect of compaction on soybean growth is more when the water supply is reduced. In this experiment water was not a limiting factor as polybags were watered regularly. Therefore the level of compaction applied by nursery workers during polybag filling could have only very limited impact on shoot growth as long as the plants are watered adequately.

Lateral root weight has increased after cut-back and the increase is more in the compacted media while the $\mathrm{W}_{\text {feed }}$ has decreased after cut-back and the decrease is more in the loosely packed media (Table 5). Root growth of the seedling plants has not been affected by the level of compaction. However, both $\mathrm{W}_{\text {feed }}$ and $\mathrm{W}_{\text {lat }}$ at 6 weeks after cutback were high in compacted polybags compared to those in loosely packed polybags (Table 3 and 5). Plants reduce their root density after cut-back (Dharmakeerthi et al. 2008) due to lack of carbohydrate supply (Kandaiah et al., 1986) and/or due to diminished need for maintaining a large root system. However, an increase in $\mathrm{W}_{\text {lat }}$ after cutback in this study is contrary to our earlier observation that $\mathrm{W}_{\text {lat }}$ also decrease by about $40 \%$ at 6 weeks after cut-back (Dharmakeerthi et al., 2008). In the earlier experiment we used subsoil from Boralu series soil which contained some \% of gravel and the plants were also subjected to a restacking stress. In non re-stacked plants, as the case in this study, a considerable $\%$ of root system is also present outside the polybag in the ground and this could exert a profound effect on the shoot and root growth compared to restacked plants. 
R S Dharmakeerthi et al.

Table 5. Shoot and root growth and shoot-root ratio as affected by level of compaction at two different growth stages of young budding plants

\begin{tabular}{|c|c|c|c|c|c|c|c|}
\hline \multirow{2}{*}{$\begin{array}{l}\text { Level of } \\
\text { Compaction }\end{array}$} & $\mathbf{D}_{\text {shoot }}$ & $\mathbf{W}_{\text {shoot }}$ & $\mathbf{W}_{\text {tap }}$ & $\mathbf{W}_{\text {lat }}$ & $\mathbf{W}_{\text {feed }}$ & $\mathbf{W}_{\text {tot }}$ & \multirow[t]{2}{*}{$\mathbf{S} / \mathbf{R}$} \\
\hline & $\mathrm{mm}$ & \multicolumn{5}{|c|}{ 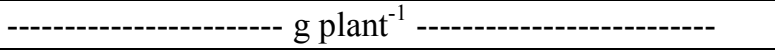 } & \\
\hline \multicolumn{8}{|c|}{12 weeks after planting } \\
\hline Loose & $6.8^{\mathrm{A}}$ & $8.92^{\mathrm{A}}$ & $1.76^{\mathrm{A}}$ & $0.13^{\mathrm{A}}$ & $0.95^{\mathrm{A}}$ & $1.08^{\mathrm{A}}$ & $3.34^{\mathrm{A}}$ \\
\hline \multirow[t]{2}{*}{ Compacted } & $6.9^{\mathrm{A}}$ & $8.67^{\mathrm{A}}$ & $1.74^{\mathrm{A}}$ & $0.16^{\mathrm{A}}$ & $0.75^{\mathrm{A}}$ & $0.91^{\mathrm{A}}$ & $3.35^{\mathrm{A}}$ \\
\hline & \multicolumn{7}{|c|}{6 weeks after cut-back } \\
\hline Loose & $4.5^{\mathrm{A}}$ & $2.43^{\mathrm{A}}$ & $4.67^{\mathrm{A}}$ & $0.21^{\mathrm{B}}$ & $0.33^{\mathrm{B}}$ & $5.21^{\mathrm{A}}$ & $0.47^{\mathrm{A}}$ \\
\hline Compacted & $4.8^{\mathrm{A}}$ & $2.81^{\mathrm{A}}$ & $5.04^{\mathrm{A}}$ & $0.43^{\mathrm{A}}$ & $0.65^{\mathrm{A}}$ & $6.13^{\mathrm{A}}$ & $0.50^{\mathrm{A}}$ \\
\hline
\end{tabular}

Values followed by the same letter in a column and within an age category are not significantly different at $\mathrm{p}<0.05$

It appears that plants grown in compacted media tends to retain more feeder roots and even promote the growth of more lateral roots, after cutback, than those plants in the loosely packed media. Feeder roots in compacted media were thicker than those in loosely packed media as observed by the dry weight per unit length (data not shown). Several others also have observed an increase in root diameter in response to increasing soil strength (Atwell, 1990; Bennie, 1991; Materechera et al., 1992). The observed high feeder root density $\left(\mathrm{W}_{\text {feed }}\right)$ in compacted media after cut-back could therefore be due to the changes in root morphology more than an increase in root length.

Compaction had not significantly affected percentages of buddable plants, grafting success, sprouting or scion death.

\section{Conclusions}

Currently used potting media in most commercial rubber nurseries is the topsoil available at the vicinity. These soils are often unfertile with very poor physical properties and this also had lead to poor growth of polybag plants produced in these nurseries. Polybag plants having a larger root system and better shoot growth would not only improve the success rate of field establishment but also enhance the adoptability to adverse environmental stresses. This study showed that both shoot and root growth of young budding plants could significantly be improved by using a potting media of soil and coir dust with a ratio of $3: 1$. Incorporation of saw dust with soil has not significantly improved the growth of young budding plants compared to those in the soil only polybag under the conditions of this study. Although the degree of compactness in the polybag could be varied during bag filling, it does not 
Potting media and compaction on growth of young buddings

significantly affect growth of the plant as long as plants are watered adequately.

\section{Acknowledgements}

The help given by Mr Keminda Herath and Dr Wasana Wijesuriya during the statistical analysis is gratefully acknowledged.

\section{References}

Atwell, B J (1990). The effect of soil compaction on wheat during early tillering. I. Growth, development and root structure. New Phytologist 115, 2935.

Bennie, A T P (1991). Growth and mechanical impedance. In: The Plant Root, The Hidden Half, pp. 393-414 (Eds. Y. Waisel, A. Eshel and U. Kafkafi). Marcel Dekker, NY.

Blouin, V, Schmidt, M, Bulmer C and Krzic, M (2004). Soil compaction and water content effects on lodgpole pine seedling growth in British Columbia [CD-ROM computer file]. SuperSoil 2004: 3rd Australian New Zealand Soils Conference, December 5-9, 2004, University of Sydney, Australia.

Buttery, B R, Tan, C S, Drury, C F, Park, S J, Armstrong, R J and Park, K Y (1998). The effects of soil compaction, soil moisture and type on growth and nodulation of soybean and common bean. Canadian Journal of Plant Science 78, 571-576.

Dharmakeerthi, R S, Yogaratnam, N, Samarappuli, L, Silva, S N, and Yakandawala, A (1997). Comparison of the effectiveness of liquid and granule fertilizer mixtures on rubber plants raised by young budding technique. Journal of the Rubber Research Institute of Sri Lanka 79, 62-70.

Dharmakeerthi, R S, Indraratne, S P and Kumaragamage, D (2007). Manual of Soil Sampling and Analysis, Soil Science Society of Sri Lanka, Peradeniya, Sri Lanka.

Dharmakeerthi, R S, Senevirathna, A M W $\mathrm{K}$, Edirimanne, V U and Chandrasiri, J A $S$ (2008). Effect of stock pruning on shoot and root growth of budded polybag plants of Hevea brasiliensis. Natural Rubber Research 21, 24-31.

Gracean, E L and Sands, R (1980). Compaction of forest soils. A review. Australian Journal of Soil Research 18, 163-189.

Hettiarachchi, R P (2002). Evaluation of organic materials for the improvement of soil fertility in rubber cultivation. MPhill Thesis. University of Sri Jayawardanapura, Sri Lanka.

Jeevartnam, A J (1962). Manuring and wind damage. Quarterly Journal of the Rubber Research Institute of Ceylon 38, 62-66.

Kandiah, S, Wettasinghe, D T and Wadasinghe, G (1986). Root influence on shoot development in tea (Caellia sinensis (L.) O. Kuntze) following shoot pruning. Sri Lanka Journal of Tea Science 55, 94-102.

Kay, B D (1998). Soil structure and organic carbon: a review. . In: R Lal, J.M. Kimble, R.F. Follet, B.A. Stewart, (Editors) Soil Processes and the Carbon Cycle. CRC Press, Boca Raton, FL. pp. 169-197.

Materachera, S A, Alston, A M, Kirby, J M and Dexter, A R (1992). Influence of root diameter on the penetration of seminal roots into a compacted subsoil. Plant and Soil 144, 297-303. 
R S Dharmakeerthi et al.

SAS Institute Inc. (1996). SAS systems for Microsoft Windows. Release 6.12. SAS Institute Inc., Cary, NC.

Samarappuli, L, Yogaratnam, N, Karunadasa, P and Mitrasena, P (1996). Root development in Hevea brasiliensis in relation to management practices. Journal of the Rubber Research Institute of Sri lanka 77, 93-111.

Soong, N K (1976). Feeder root development of Hevea brasiliensis in relation to clones and environment. Journal of Rubber Research Institute of Malaysia 24, 283-298.

Tillekaratne, L M K and Nugawela, A (2001). Handbook of Rubber Volume 1: Agronomy. Rubber Research Institute of Sri Lanka, Agalawatta, Sri Lanka.

Varghese, M, Punnoose, K I and Pothen, J (2005). Rooting characteristics of polybagged plants of Hevea brasiliensis. Natural Rubber Research 18, 1-6.

Veihmeyer, F J and Hendrickson, A H (1948). Soil density and root penetration. Soil Science 65, 487.

Yogaratnam, N, Silva, F P W and Weerasuriya, S M (1984). Recent developments in the nutrition of Hevea in Sri Lanka. Proceedings of the International Rubber Conference Vol. 1 Part (1) September 17-19, Colombo, Sri Lanka. Rubber Research Institute of Sri Lanka. pp 207-247.

Address for correspondence: $\mathrm{Dr} \mathrm{R} \mathrm{S}$ Dharmakeerthi, Soils Chemist, Rubber Research Institute of Sri Lanka, Dartonfield, Agalawatta, Sri Lanka.

E-mail: sdharmakeerthi@sltnet.lk 